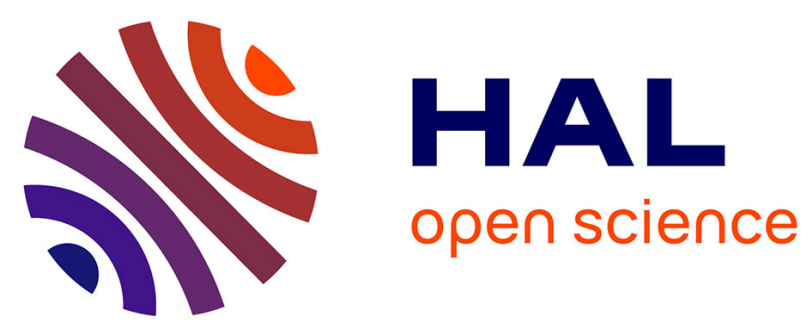

\title{
Multiple HBV transfusion transmissions from undetected occult infections: revising the minimal infectious dose
}

Daniel Candotti, Sonny Michael Assennato, Syria Laperche, Jean-Pierre Allain, Snezna Levicnik-Stezinar

\section{To cite this version:}

Daniel Candotti, Sonny Michael Assennato, Syria Laperche, Jean-Pierre Allain, Snezna LevicnikStezinar. Multiple HBV transfusion transmissions from undetected occult infections: revising the minimal infectious dose. Gut, 2019, 68 (2), pp.313-321. 10.1136/gutjnl-2018-316490 . inserm-03555588

\section{HAL Id: inserm-03555588 https://www.hal.inserm.fr/inserm-03555588}

Submitted on 3 Feb 2022

HAL is a multi-disciplinary open access archive for the deposit and dissemination of scientific research documents, whether they are published or not. The documents may come from teaching and research institutions in France or abroad, or from public or private research centers.
L'archive ouverte pluridisciplinaire HAL, est destinée au dépôt et à la diffusion de documents scientifiques de niveau recherche, publiés ou non, émanant des établissements d'enseignement et de recherche français ou étrangers, des laboratoires publics ou privés. 


\title{
Multiple HBV transfusion transmissions from undetected occult infections: revising the minimal infectious dose
}

\author{
Daniel Candotti, ${ }^{1}$ Sonny Michael Assennato, ${ }^{2}$ Syria Laperche, ${ }^{1}$ Jean-Pierre Allain, ${ }^{2}$ \\ Snezna Levicnik-Stezinar ${ }^{3}$
}

'Department of Blood

Transmitted Agents, National Institute of Blood Transfusion, Paris, France

${ }^{2}$ Department of Haematology, University of Cambridge, Cambridge, UK

${ }^{3}$ Blood Transfusion Centre of Slovenia, Ljubljana, Slovenia

Correspondence to

Dr Daniel Candotti, Department of Blood Transmitted Agents,

National Institute of Blood Transfusion, 75015 Paris, France; dcandotti@ints.fr

Received 16 April 2018 Revised 25 May 2018 Accepted 28 May 2018 Published Online First 29 June 2018

\section{Linked}

- http://dx.doi.org/10.1136/ gutjnl-2018-316900

Check for updates

To cite: Candotti $\mathrm{D}$ Assennato SM, Laperche $S$, et al. Gut 2019:68:313-321.

\begin{abstract}
Objective HBV infection by blood components is currently prevented in most developed countries by combining sensitive HBV surface antigen ( $\mathrm{HBsAg}$ ) assays, nucleic acid testing (NAT) and in a few of them antibodies against the HBV core antigen (anti-HBC) screening. HBV transmissions by blood components from three repeat donors tested negative for HBsAg and HBV DNA with a highly sensitive screening test (limit of detection (LOD): $3.4 \mathrm{IU} / \mathrm{mL}$ ) were investigated.

Design 30 of the 47 recipients of components produced from these three donors were examined. Transfusion transmission was confirmed by phylogenetic analysis of viral sequences obtained from recipients and donors following viral particle concentration.

Results 9 of 31 (29\%) recipients were infected: 7 infections were related to $200 \mathrm{~mL}$ of fresh frozen plasma and 2 infections to red blood cells containing $20 \mathrm{~mL}$ plasma. Transfusion transmission was confirmed by $>99 \%$ identity of donor/recipient sequences in five cases, probable in three and possible in one. HBV active infection remained unsuspected for 24-57 months in three recipients. Five non-infected recipients carried anti-HBs when transfused. Six patients transfused with platelet concentrates treated with a pathogen reduction method were not infected. These data enabled to revise previous estimate of the minimal infectious dose from approximately 100 to 16 copies (or 3 IU) of HBV DNA. Conclusions HBV transfusion transmission from occult HBV infection carrying extremely low viral loads is related to plasma volume transfused and possibly prevented by anti-HBs. HBV blood safety could be further improved by either anti-HBc screening, HBV DNA NAT with a LOD of 0.8 copies $/ \mathrm{mL}(0.15 \mathrm{IU} / \mathrm{mL})$ or pathogen reduction of blood components.
\end{abstract}

\section{INTRODUCTION}

Hepatitis B remains a global major public health issue and a viral infection transmissible by transfusion. ${ }^{1}$ The risk of HBV transfusion transmitted infection (TTI) has been reduced by (1) the risk behaviour-based selection of donors; (2) the continuous improvement of serological assays to detect the HBV surface antigen (HBsAg); (3) the implementation of anti-HBc screening for antibodies against the HBV core antigen (anti-HBc) when appropriate according to the epidemiological context and (4) the implementation of viral nucleic acid testing
Significance of this study

What is already known on this subject?

- HBV transfusion transmission with blood components from donors with occult HBV infection has been reported.

- An estimated $50 \%$ minimum HBV infectious dose of 1049 (range: 117-3441) virions per transfusion has been proposed.

- HBV infection by blood components is currently prevented in most developed countries by combining sensitive HBV surface antigen ( $\mathrm{HBsAg}$ ) assays, nucleic acid testing and in a few of them anti-HBC (HBV core antigen) screening.

- Clinical observations and mathematical models suggested that blood components from donors with occult HBV infection undetected by highly sensitive serological and molecular screening assays might transmit HBV infection.

What are the new findings?

- Clinical and molecular confirmation of HBV transmission in several patients transfused with red blood cells and fresh frozen plasma from repeat donors with occult HBV infection undetected over the years by the most sensitive serological and molecular screening assays available.

- The estimated minimum HBV infectious dose by transfusion was revised from approximately 100 to 16 copies (or 3 IU) of HBV DNA.

- Transfusion transmission of undetected occult $\mathrm{HBV}$ infections resulted in overt (HBsAg and viral DNA positive) infections in recipients who remained unsuspected and untreated for years.

(NAT) as multiplex assays detecting simultaneously HBV, HCV and HIV genomes applied either to pools of plasma samples or, more efficiently, to individual donations (IDs). HBV NAT improved blood safety by reducing the serological window period (WP) from 32 to 15 days in donors with acute infection ${ }^{2}$ and by uncovering donors with occult HBV infection (OBI). ${ }^{3}$ OBI appears to be a phase of the intrahepatic viral life cycle in which viral replication and gene expression are strongly 
Significance of this study

\section{How might it impact on clinical practice in the foreseeable future?}

- HBV blood safety could be improved by anti-HBC screening in low endemic settings, development of HBV nucleic acid testing with limit of detection $<1$ copy $/ \mathrm{mL}(0.2 \mathrm{IU} / \mathrm{mL})$ and implementation of pathogen reduction procedures of blood components.

- Implementation of efficient haemovigilance procedures including systematic collection and long-term storage of a pretransfusion plasma sample from patients for HBV transmission monitoring and patients' therapeutic management.

but imperfectly controlled by the host immune system and/or related to viral variants. ${ }^{4}$

Confirmed or deemed highly probable HBV transfusion transmission with blood components from OBI donors has been reported. $^{25-13}$ Due to methodological differences and intrinsic limitations between studies, the estimated OBI transmission rate for all components varied between $3 \%$ and $48 \%$. OBI transmission rate depends on the transfused viral dose (viral load $\times$ plasma volume transfused), the presence of anti-HBs in donor and/or recipients and the general immune status of the recipient. ${ }^{10} 1415$ However, transmission rate might be underestimated due to the lack of proper identification of $\mathrm{HBV}$ infection in recipients, the absence of recipient pretransfusion sample to exclude pre-existing infection, the difficulty and reluctance to trace recipients, the lack or limited volume of donor archive samples and undetectable or intermittently detectable HBV DNA in donors. ${ }^{16}$ An estimated 50\% minimum HBV infectious dose of 1049 (range: 117-3441) virions has been proposed based on TTI look-back studies. ${ }^{10}$ However, studies suggested that OBI-infected blood products with HBV DNA load undetected even by highly sensitive NAT might transmit $\mathrm{HBV}^{2}{ }^{21} 1217$ A recent mathematical model estimated that $3.3 \%$ and $14 \%$ of OBI donations undetected by NAT with a $95 \%$ limit of detection (LOD) of $3.4 \mathrm{IU} /$ $\mathrm{mL}$ (18 copies/mL) might cause infection by a blood component containing $20 \mathrm{~mL}$ and $200 \mathrm{~mL}$ of plasma, respectively. ${ }^{18}$

This study presenting HBV transmission to nine recipients by blood components from three Slovenian blood donors with OBI remaining undetected by highly sensitive NAT allows to reconsider the minimal HBV infectious dose and the NAT sensitivity required to prevent $\mathrm{HBV}$ transmission by transfusion.

\section{MATERIALS AND METHODS Blood donation screening}

Slovenian candidate donors provided written consent for their blood and/or donation data to be used for scientific research. Donations were screened for HBsAg and HBV DNA using ABBOTT PRISM HBsAg (Abbott Laboratories, Delkenheim, Germany) chemiluminescent immunoassay (LOD: $0.022 \mathrm{IU} / \mathrm{mL}$ ) and ID-NAT with the HIV-1/HCV/HBV multiplex Procleix-Ultrio assay (2007-2012 period) and the Procleix-Ultrio Elite assay (2013-2017 period) (Hologic/Gen-Probe, San Diego, California, USA; and Grifols Diagnostics, Emeryville, California, USA). The 95\% LOD for HBV DNA reported by the manufacturer is 10.4 $\mathrm{IU} / \mathrm{mL}$ and $3.4 \mathrm{IU} / \mathrm{mL}$ for each assay, respectively. The viral genome present in samples' initially reactive was identified using the Procleix HIV-1, HCV and HBV discriminatory assays with LODs similar to the multiplex assay.

\section{HBV confirmatory testing}

HBsAg with an alternative assay as well as anti- $\mathrm{HBc}$ total, anti-HBc IgM, quantitative antibodies against the HBV surface antigen (anti-HBs), antibodies against the $\mathrm{HBV}$ e antigen (anti-HBe) and HBeAg tested with Abbott Architect in archived and/or follow-up plasma samples from donors and recipients were performed. For anti-HBc, being reactive twice was considered confirmatory.

HBV DNA was purified from $200 \mu \mathrm{L}$ of recipients' plasma and from 2 to $24 \mathrm{~mL}$ of donors' plasma after viral particle concentration by high-speed centrifugation. ${ }^{19} \mathrm{HBV}$ basic core promoter/ precore $(\mathrm{BCP} / \mathrm{PC})$, pre- $\mathrm{S} / \mathrm{S}$ and $\mathrm{S}$ regions and the whole $\mathrm{HBV}$ genome were amplified, sequenced and phylogenetically analysed. ${ }^{19}{ }^{20}$ The 107 reference sequences used for comparison were selected from GenBank and included 68 sequences of subgenotype $\mathrm{D} 2\left(\mathrm{HBV}_{\mathrm{D} 2}\right)$ that appeared genotypically closest to our patient and donor sequences by BLAST (https://blast.ncbi.nlm. nih.gov/Blast.cgi).

HBV DNA load was quantified with both the Cobas Taqman HBV (Roche Diagnostics, Mannheim, Germany) and an in-house real-time quantitative PCR (qPCR) assay. ${ }^{20}$

\section{RESULTS}

\section{Case 1}

In March 2013, patient R1-1 was hospitalised with hepatorenal syndrome and newly developed jaundice. Testing positive for $\mathrm{HBsAg}$, total anti-HBc, anti-HBc IgM and anti-HBe, the patient was diagnosed as clinical acute HBV infection (table 1). Plasma HBV DNA load was $8.12 \times 10^{5} \mathrm{IU} / \mathrm{mL}$. He was treated with lamivudine, and anti-HBs seroconversion occurred 5 months later.

In July 2013, the same hospital reported a similar case in recipient R1-2 who presented with clinical signs of acute hepatitis identified as related to HBV by positive testing for HBsAg, total anti-HBc, anti-HBc IgM and anti-HBe (table 1). HBV DNA load was $1.04 \times 10^{3} \mathrm{IU} / \mathrm{mL}$ and the patient was treated with entecavir leading to anti-HBs seroconversion.

Investigations to determine the origin of both $\mathrm{HBV}$ infection cases uncovered that, following surgery, patients R1-1 and R1-2 were transfused with fresh frozen plasma (FFP) 4 (November 2012) and 5 months (February 2013) before acute hepatitis B diagnosis, respectively. Prior HBV exposure was excluded by the absence of detectable HBV markers in the two recipients' plasma samples archived before surgery and transfusion (table 1). Recipients R1-1 and R1-2 were transfused with FFP from two blood donations collected in August 2012 and January 2013 from a repeat donor (BD1). Retrospective serological and molecular analyses performed in repository samples of the suspected donations and in two previous donations collected in August 2011 and February 2012 showed negative results for HBsAg, HBeAg, anti-HBe and anti-HBs but detected anti-HBc. HBV DNA was consistently undetectable in all samples from donations collected between August 2011 and December 2013 tested with the commercial Procleix-Ultrio Elite ID-NAT screening assay and retrospectively tested with an in-house qPCR assay (LOD: $<10 \mathrm{IU} / \mathrm{mL}$ ).

Donor BD1 HBV DNA was investigated further after highspeed centrifugation of plasma collected in April 2013. A 276-nucleotide BCP/PC fragment was amplified and sequenced confirming HBV DNA presence in donor BD1 plasma. This result was confirmed by repeating the $\mathrm{BCP} / \mathrm{PC}$ amplification and by obtaining a 445 -nucleotide fragment of the $S$ gene when $20 \mathrm{~mL}$ of plasma collected in January 2014 were enriched by ultracentrifugation prior to DNA purification. The complete 


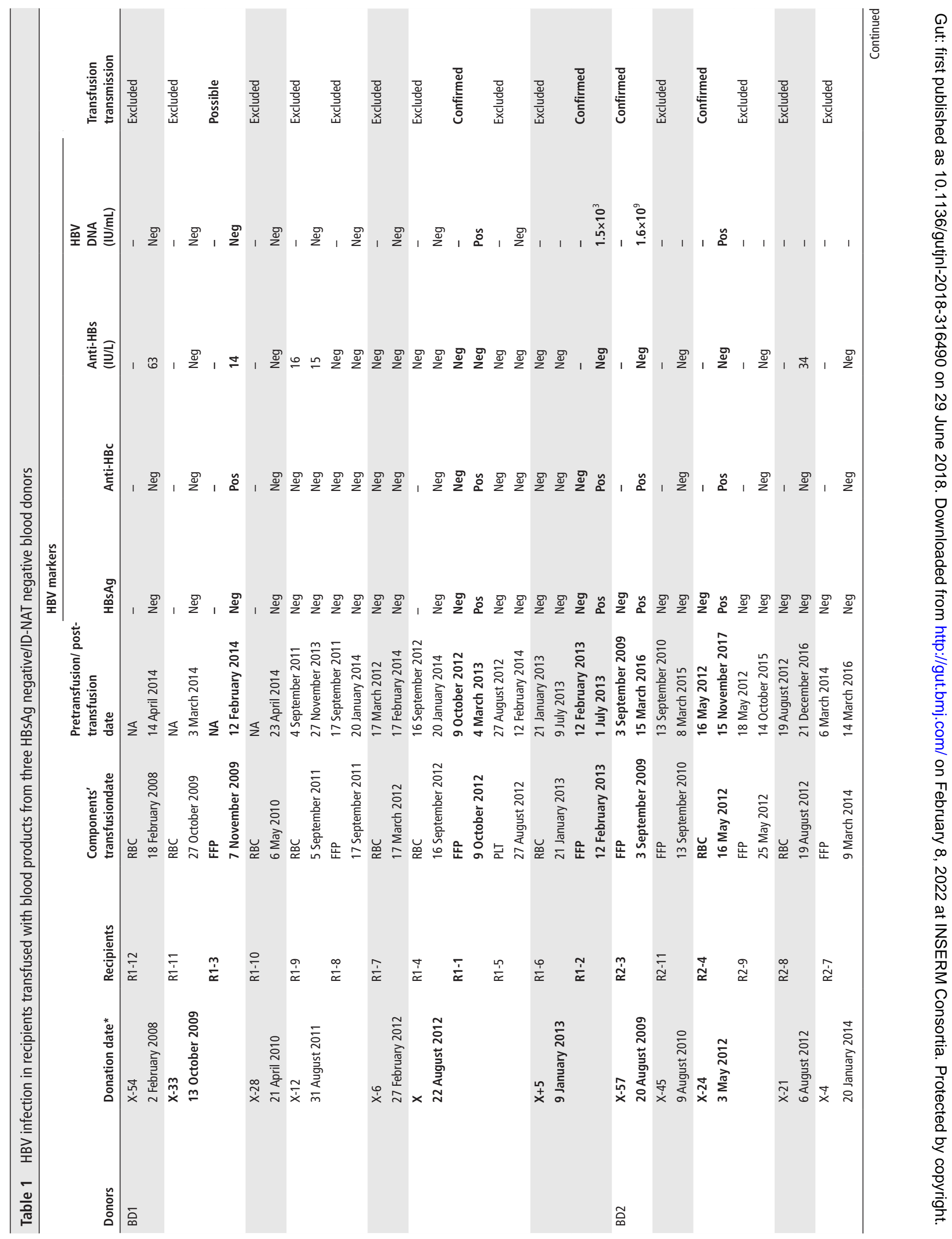




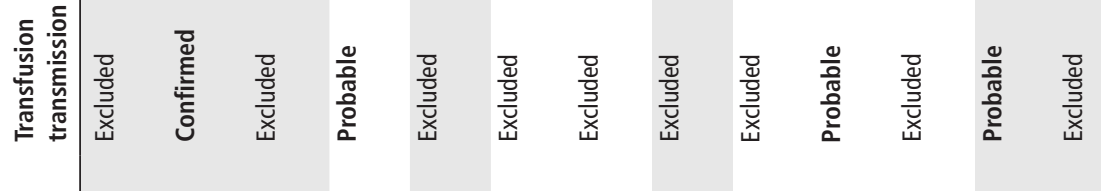

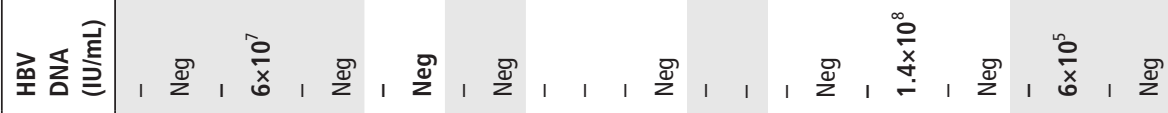

耪高

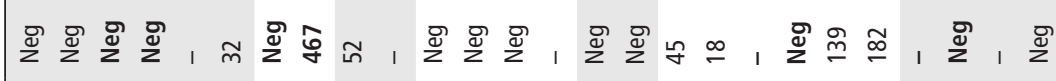

妾

ه্

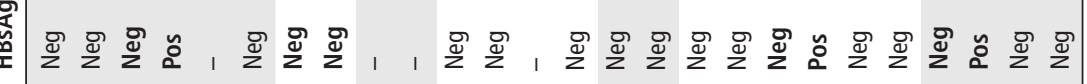
京

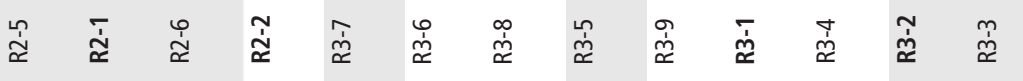
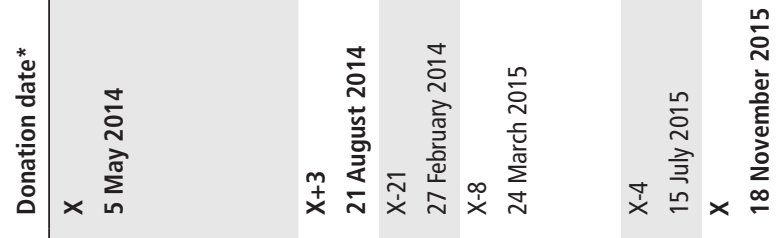
genomes of the HBV strains infecting recipients R1-1 and R1-2 were amplified separately and sequenced. These two sequences presented $99.9 \%$ nucleotide identity and phylogenetic analysis identified HBV genotype D, subgenotype D2 (figure 1).

Donor BD1 and recipients R1-1 and R1-2 showed identical $\mathrm{BCP} / \mathrm{PC}$ sequences with the presence of the mutation G1896A generating a stop codon in the PC. Donor and recipients' $S$ sequences were aligned with $107 \mathrm{HBV}$ reference sequences. Donor and recipients' sequences shared 99.55\% nucleotide identity and clustered together among the $\mathrm{HBV}_{\mathrm{D} 2}$ clade even if bootstrap values were $<70 \%$ due to the limited length of the sequence analysed (445 nucleotides) (figure 2). Overall data evidenced that recipients R1-1 and R1-2 were infected with the same virus and strongly supported a genetic link between the viral strains infecting donor BD1 and these recipients.

All three translated amino acid (aa) sequences presented with a signature substitution (sV177L) that was not found in any of the $68 \mathrm{HBV}_{\mathrm{D} 2}$ control sequences. However, BD1 aa sequence differed from the two recipients (R1-1 and R1-2) in two $S$ protein major hydrophilic region locations: sR122K and sY134H. This particular substitution was present in 10/42 genotype D OBI but none of 129 chronic HBV infection D strains. In contrast, full genome sequences of R1-1 and R1-2 shared aa pI601V, pV613I and pT657S as well as sL213S substitutions not found in BD1 nor in the $\mathrm{HBV}_{\mathrm{D} 2}$ reference sequences. R1-1 also differed from R1-2 by the pE553K substitution.

Look-back data were obtained from nine additional patients transfused with blood products derived from BD1. Seven patients transfused with six red blood cells (RBC) and one platelet (PLT) concentrates prepared between October 2009 and January 2013 showed no evidence of HBV infection 6-18 months post-transfusion (table 1). Two units of FFP were transfused to recipients R1-3 and R1-8. R1-3, transfused with an FFP unit collected nearly 3 years prior to index donation, was tested 50 months post-transfusion and found negative for HBsAg and HBV DNA but positive for total anti-HBc and anti-HBs (14 IU/L) suggesting recovered HBV infection. However, no pretransfusion sample was available to eliminate the possibility of pretransfusion exposure to the virus and post-transfusion infection from another source cannot be ruled out. Recipient R1-8 transfused with an FFP unit collected 1 year prior to index donation remained HBV negative.

\section{Case 2}

In April 2015, a patient in chronic renal dialysis was found to be $\mathrm{HBV}$ infected (HBsAg positive, $\mathrm{HBeAg}$ positive, anti-HBc positive and HBV DNA $\left.6 \times 10^{7} \mathrm{IU} / \mathrm{mL}\right) 8$ months after been transfused with FFP in August 2014 (table 1). A complete HBV genome sequence was obtained. This patient, designed as recipient R2-1, tested negative for HBV markers 1 month before transfusion. The suspected FFP donor (BD2) was a repeat donor who donated 21 times between 2009 and 2014 (index donation May 2014). All donations tested negative for HBsAg and HBV DNA. Repository samples available for nine donations collected before 2013 were non-reactive when tested retrospectively with Ultrio Elite assay (data not shown). However, the index donation and a repository sample from a previous donation (X-57 months, August 2009) tested anti-HBc positive. Donor BD2 donated three more times during the 8 -month period following index donation before TTI was suspected. RBC and FFP products prepared from two HBV negative donations $\mathrm{X}+3$ (August 2014) and X+7 (December 2014) were transfused to three recipients. As indicated in table 1 , look-back data were available only for recipient R2-2 transfused with FFP (X+3, August 2014). A third HBsAg-negative donation (X+11 months, April 2015) was discarded after being tested initially reactive with the ID-NAT multiplex screening assay but non-reactive with the discriminatory assay. Multiple repeat testing of $\mathrm{X}+11$ plasma with Ultrio Elite showed three reactive of 28 replicates (10.7\%). Donation $\mathrm{X}+11$ was confirmed anti-HBc positive and the complete HBV genome sequence minus 340 nucleotides (nt1538-nt1877) was obtained after concentrating viral particles.

Overall, data were obtained for $6 / 8,3 / 15$ and $1 / 3$ recipients of FFP, RBC and PLT units, respectively (table 1 ). Three of six recipients of FFP and one of three recipients of RBC examined presented evidence of post-transfusion HBV infection. Recipient R2-2 was transfused with an FFP unit from donation $\mathrm{X}+3$ months following surgery. R2-2 tested negative for HBV markers before transfusion but 16 months post-transfusion was positive for anti-HBc, anti-HBe and anti-HBs (467 IU/L) without detectable HBsAg and viral DNA suggesting recovered HBV infection. No HBV sequence could be obtained. Recipient R2-3 received FFP in September 2009 from donation X-57 months following surgery. R2-3 was reported HBsAg negative before transfusion, but this sample was not available for additional testing. A blood sample collected 6.5 years later tested positive for $\mathrm{HBsAg}$, anti-HBc and HBV DNA $\left(1.6 \times 10^{9} \mathrm{IU} / \mathrm{mL}\right)$. The HBV complete genome sequence was obtained. Recipient R2-4 received RBC in May 2015 from BD2 donation X-24 months and was reported HBsAg negative prior to transfusion. In November 2017 (5.5 years post-transfusion), he was found positive for $\mathrm{HBsAg}$, anti-HBc, $\mathrm{HBeAg}$ and $\mathrm{HBV}$ DNA, and negative for anti-HBe and anti-HBs. The HBV complete genome was amplified and sequenced.

Phylogenetic analysis showed that donor BD2 and recipients R2-1, R2-3 and R2-4 sequences clustered together (100\% bootstrap value over 1000 replicates) within genotype D2 clade (figure 1). Based on 2842 nucleotides common to all four strains, BD2 sequence had $99.9 \%$ nucleotide identity with R2-1 and R2-4 sequences (two divergent nucleotides) and 99.8\% identity (four divergent nucleotides) from R2-3 sequences. The complete sequences of R2-1, R2-3 and R2-4 had 99.9\% identity (two nucleotide differences). Envelope proteins of the cluster were identical except R2-1 sS193L substitution, and R2-3 differed from the other three sequences by aa pR9P and pM253N in the polymerase. BD2 aa sequence carried a unique S31P in the $\mathrm{X}$ protein.

\section{Case 3}

In September 2016, two hospitals reported post-transfusion acute HBV infection in two patients (R3-1 and R3-2) treated for cardiac and thoracic surgery, respectively. Pretransfusion repository samples of these patients tested negative for HBsAg and anti-HBc (table 1). Six months post-transfusion, R3-1 and R3-2 were found HBsAg and anti-HBc IgM reactive with HBV DNA loads of $1.4 \times 10^{8}$ and $6 \times 10^{5} \mathrm{IU} / \mathrm{mL}$, respectively. The R3-1 and R3-2 complete HBV genome sequences were of genotype D2 with $99.8 \%$ nucleotide identity. Both sequences presented no particular feature when compared with the $\mathrm{HBV}_{\mathrm{D} 2}$ references, except for the presence of a specific $\mathrm{R} 122 \mathrm{~K}$ substitution in the $\mathrm{S}$ protein.

Traceback investigation revealed that recipients R3-1 and R3-2 had been transfused with an FFP unit collected in November 2015 and an RBC unit collected in March 2016 from the same donor BD3, respectively. The plasma from the November 2015 donation tested also negative with COBAS TaqMan HBV and in-house qPCR assays. This sample and a plasma sample collected 11 months later 


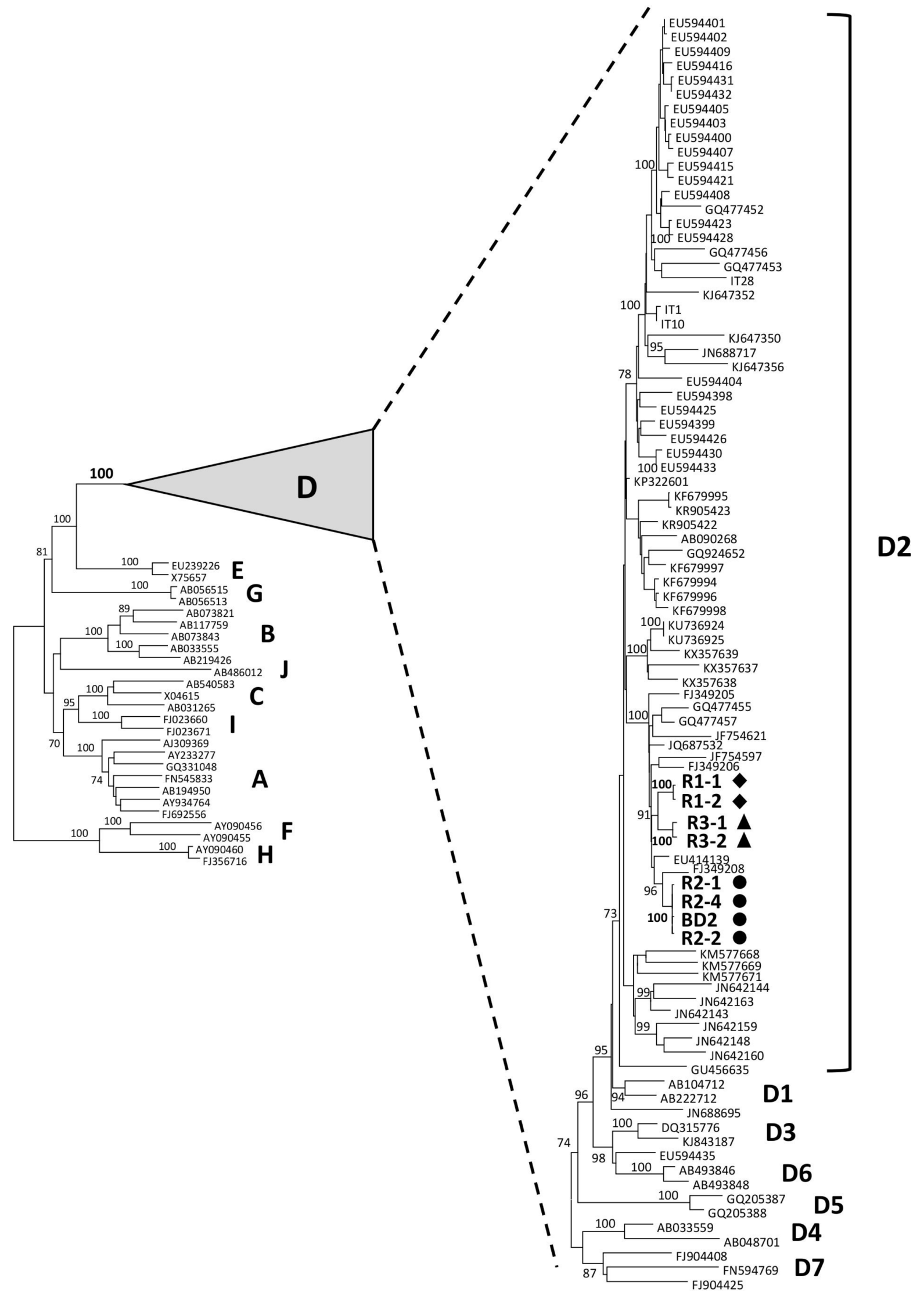

Figure 1 Phylogenetic tree of HBV sequences from infected blood donors and recipients. Sequences included the nearly complete viral genome (2842 nucleotides). Phylogenetic analysis was performed by the neighbour-joining algorithm based on the Kimura two-parameter distance estimation method. Only bootstrap values of $>70 \%$ are shown (1000 replicates). Reference sequences were taken from GenBank and indicated by their accession code, and genotypes and subgenotypes are indicated. indicates donor BD1 and recipients R1-1 and R1-2 sequences; indicates donor BD2 and recipients R2-1, R2-3 and R2-4; and $\mathbf{\Delta}$ indicates recipients R3-1 and R3-2. 


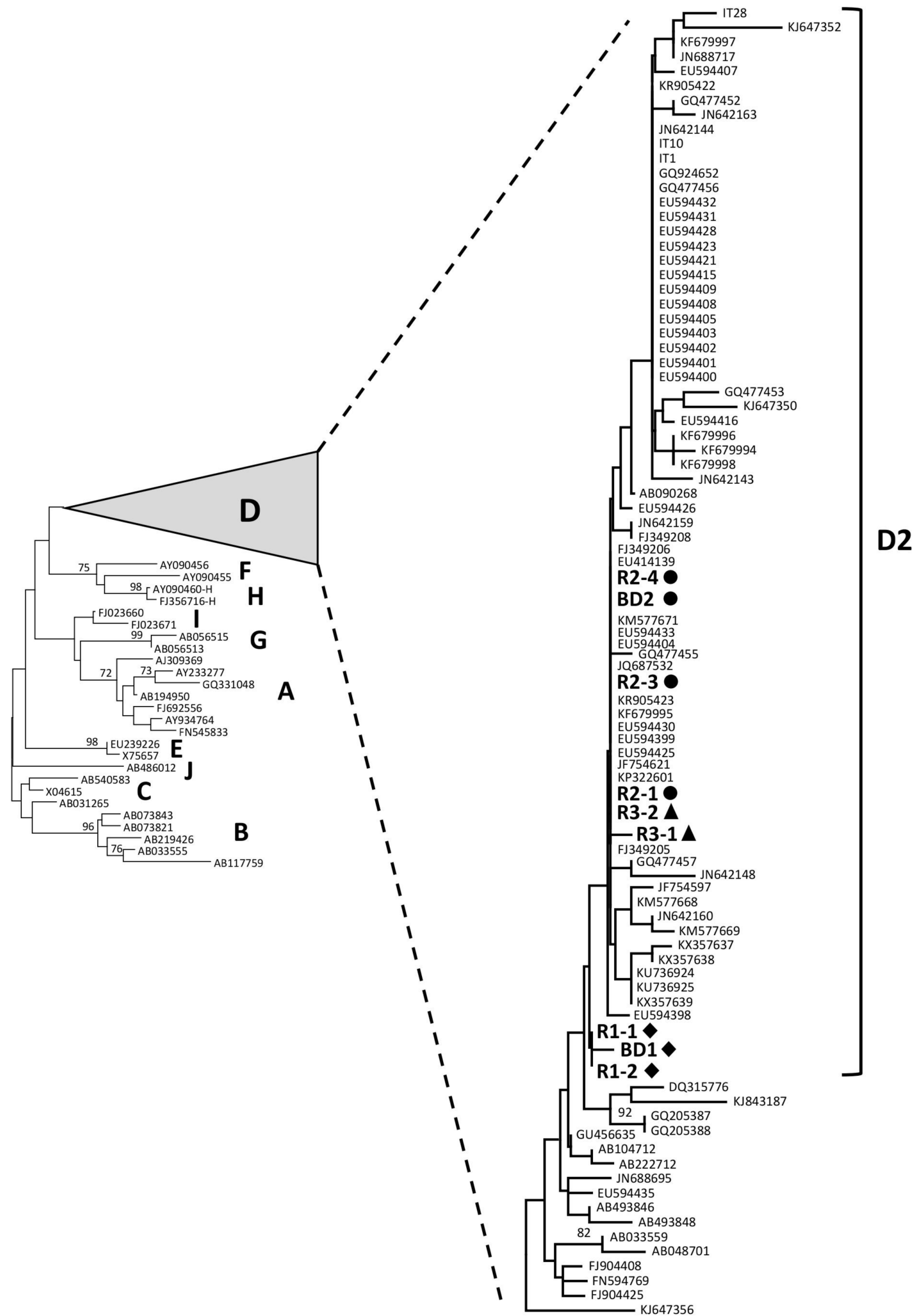

Figure 2 Phylogenetic tree of partial S sequences (445 nucleotides) from infected blood donors and recipients. Phylogenetic analysis was performed as described in figure 1. 
Table 2 HBV infection in 31 patients (24 anti-HBs negative and 7 anti-HBs positive) transfused with blood products from three $\mathrm{HBsAg}$ and HBV DNA non-reactive donors

\begin{tabular}{lllll}
\hline \multirow{3}{*}{ Recipients } & FFP & RBC & PLT $^{*}$ & Total \\
\cline { 2 - 4 } Anti-HBs pos & - & $0 / 4$ & $0 / 3$ & $0 / 7$ \\
Anti-HBs neg & $7 / 11(64 \%)$ & $2 / 10(20 \%)$ & $0 / 3$ & $9 / 24(37.5 \%)$ \\
& & & - &
\end{tabular}

*Pathogen reduction treatment of PLT concentrates.

FFP, fresh frozen plasma; HBsAg, HBV surface antigen; Neg, negative; PLT, platelet; Pos, positive; RBC, red blood cell.

were both found anti-HBc positive. HBV DNA detection failed in 1-24 mL plasma samples collected either for repository or as follow-up in October 2015 and January 2017. Look-back investigations of seven additional recipients of four PLTs and three RBC units from donations collected between February 2014 and March 2016 did not show evidence of HBV transfusion transmission. However, recipients R3-4 and R3-9 transfused with PLT and RBC from the index donation (November 2015) carried 139 and 45 IU/L anti-HBs, respectively (table 1 ).

Taken together, 47 patients were transfused with blood components prepared from the three reported donors. Information was obtained from 31 of them (66\%; table 1). Although complete pretransfusion data were not obtained for each patient, seven of them appeared certainly $(n=4)$ or probably $(n=3)$ carrying anti-HBs and none of them was infected. Considering the 24 remaining susceptible patients, nine $(37.5 \%)$ were definitely $(n=5)$, probably $(n=3)$ or possibly $(n=1)$ infected by transfusion. Infection rates were $64 \%$ and $20 \%$ in possibly susceptible (anti-HBs-negative) patients transfused with FFP and RBC, respectively (table 2). PLT concentrates were treated with a pathogen reduction method using amotosalen and UVA light (INTERCEPT Blood System; Cerus, Concord, California, USA) and none of the six recipients explored were infected.

\section{DISCUSSION}

Nine cases of HBV transfusion transmission from infected blood donations undetected with highly sensitive HBsAg and HBV DNA screening assays currently used were documented. During the period 2008 to 2015 included in this study, 37 OBIs were identified by NAT screening and 9 undetected by NAT identified following patient infections. The latter type of OBI represented $19.6 \%$ of overall OBIs in a total of 744668 donations screened. The identification of post-transfusion HBV infection relies primarily on clinical evidence of acute infection followed by the detection of specific markers. This clinical triggering underestimates the true incidence of post-transfusion infections. In this study, only four out of nine total cases identified were symptomatic (R1-1, R1-2, R3-1 and R3-2). Interestingly, the incubation time or interval between transfusion and clinical symptoms ranged between 137 and 198 days, which are close to or beyond the range of 50-150 days reported in textbooks. R3-2 case reached 198 days. It is possible that very small number of infectious particles received by these transfusions of donors with OBI played a role in this late development of infection.

In Slovenia, a pretransfusion plasma sample is systematically collected and archived (rules on blood transfusion research and procedures in blood transfusion: Official Gazette of the Republic of Slovenia 09/2007). This singularity provided a considerable advantage in the resolution of TTI suspected cases that was not available in any of the previously reported studies on OBI infectivity by transfusion. ${ }^{6-12}$ The availability of archive samples from both donors and recipients as well as of large-volume follow-up donor samples allowed maximum ability to detect and characterise HBV TTI associated with extremely low viral load. The sequences obtained were of genotype D (subgenotype D2) that is prevalent in Slovenian blood donors. ${ }^{21}$ Clusters of donor and recipient sequences with over $99 \%$ homology authenticated TTI in each of the three clusters investigated (figure 1). Despite the intervals between the times of collection for donor, times of transfusion for recipients and the samples from which sequences were obtained (2-16 months for BD1/R1 and 0-5.6 years for BD2/R2), very few mutations separated sequences in each of the clusters. In particular, the pair BD2 and R2-3 differed only by two nucleotides over 2842 after approximately 5 years of evolution in two distinct individuals. This data support previously recognised conclusions that even years apart, sequences with $>99 \%$ homology were highly likely to have the same origin as was exemplified in the two recipients of case 3 where no donor sequence was obtained despite concentration of a large volume of plasma sample. ${ }^{1322}$ In addition, donor BD3 being anti-HBc positive in three samples collected 3 years apart and the $99.8 \%$ nucleotide sequence homology in samples collected 5 and 6 months post-transfusion from unrelated recipients R3-1 and R3-2 transfused with two donations collected at 4-month intervals, respectively, suffice to make transfusion transmission of HBV nearly 100\% likely .

The data presented confirm the importance of a pretransfusion recipient sample, of molecular detection and sequencing of HBV strains to authenticate TTI in addition to the development of HBV markers. It also clearly indicates that an increased sensitivity of HBV DNA screening assays remains desirable in conjunction to increasing the volume of plasma extracted. Such improvement will decrease the risk of $\mathrm{HBV}$ transfusion transmission but probably will not eliminate it altogether as exemplified by case BD3. Screening for anti-HBc would have identified and excluded the three cases of infectious OBI donors reported, but screening for this marker would exclude $3 \%$ of Slovenian donors and impair a fragile blood supply. ${ }^{7}$

Look-back data available for 31 recipients (66\%) evidenced that blood donations with undetectable HBV DNA by highly sensitive NATs might transmit HBV. The model developed by Weusten and colleagues predicted that $14 \%$ of residual HBV transmission would originate from NAT negative units. ${ }^{18}$ This prediction is supported by limited data from a Japanese look-back study that found $7 / 43$ possible OBI TTI associated with donations confirmed NAT negative. ${ }^{11}$ An Australian donor-triggered study also reported possible or probable HBV TTI in nine recipients who were transfused with components from OBI donations that tested Ultrio NAT negative. ${ }^{11}$ A case of an RBC unit from an OBI donor repeatedly NAT negative by Ultrio assay and subsequently with Ultrio Plus transmitting $\mathrm{HBV}$ to a severely immunosuppressed recipient was reported. ${ }^{17}$ No molecular data were available to confirm TTI in these studies conducted with NAT assays of equal or lower analytical sensitivity than used in the present study (95\% LOD of $\sim 4-10.4 \mathrm{IU} / \mathrm{mL}$ ). A molecularly confirmed HBV transmission by an RBC unit from an OBI donation negative with Ultrio Plus NAT was reported. ${ }^{2}$

Our data showed direct or indirect evidence of HBV transfusion transmission in 9/31 recipients (29\%) of components from donations undetected by the currently most sensitive NAT, increasing to $37.5 \%$ of susceptible patients (excluding 7 recipients presumably protected by anti-HBs). As previously pointed out, infectivity was mostly found with FFP that contains approximately $200 \mathrm{~mL}$ of plasma compared with the $20 \mathrm{~mL}$ remaining in $\mathrm{RBC} .{ }^{10}$ This high rate of transmission is similar to the previously published findings of a multicentre study of OBI infectivity that was $49 \%$ when excluding $\mathrm{HBV}$ vaccinated patients and was reduced to $36 \%$ when anti-HBs negative recipients were included. ${ }^{10}$ These rates of infectivity are considerably higher than those presented in other studies without 
molecular confirmation and pretransfusion HBV markers. ${ }^{6} 91213$ However, one in four recipients of BD1 FFP and three/six recipients of BD2 FFP were not infected, suggesting that in these OBIs with very low viral load, fluctuation of HBV DNA levels was present as described in OBI with higher viral load. ${ }^{71316}$ This series of patients provided the opportunity to revise the predicted OBI infectious dose of 1049 copies (range 117-3441) or 197 IU on the basis of clinical data, ${ }^{9}$ and of 316 copies or $\sim 60$ IU when derived from a mathematical model. ${ }^{23}$

In the present study, anti-HBs-negative donors with HBV DNA plasma load $<3 \mathrm{IU} / \mathrm{mL}$ ( $<16$ copies $/ \mathrm{mL}$ ) transmitted to susceptible recipients non-immune to $\mathrm{HBV}$ and transfused with $\mathrm{RBC}$ and FFP products containing $<320$ virions and $<3200$ virions, respectively. A limitation of the study was that sample volume limitation in donation repository and the insufficient sensitivity of the viral load quantification methods did not permit precise results. However, a method was developed to calculate low-level viral load on the basis of testing multiple replicates of a sample with Ultrio Plus/Elite and derive a viral load by applying the number of positive repeat to a Probit reference curve. ${ }^{1823}$ Donor BD2 follow-up sample provided volume for multiple repeat testing (28 tests) with Ultrio Elite assays. Using probability curves of HBV DNA detection by Ultrio Elite previously determined by Probit analysis and a reactivity rate of $10.7 \%$ (3 positive results out of 28 tests), the HBV DNA concentration estimate was 0.8 copies $/ \mathrm{mL} .^{23}$ If this viral load is applied to the previous infectious donations, the infectious dose could be estimated at 16 copies and 160 copies for RBC and FFP, respectively. All other elements being equal, viral load fluctuations mentioned above might explain three infections of six transfused FFP. This conclusion would probably not account for the case of RBC transmission when the FFP prepared from the same donation was not infectious. Elements other than plasma volume, specific to the recipient such as immunodeficiency, might play a role in recipient R2-4 while protective effect of transfusion of other components containing anti-HBs might have influenced the outcome in recipient R2-9 (table 1). R2-4 was immunocompetent and received 4 units of RBC and 4 units of FFP during and after surgery. R2-9 received 10 FFP units for surgery and, a month and a half later, underwent severe immunosuppression related to organ transplantation. Repository samples from 9 FFP units showed one carrying 14 IU/L anti-HBs that might have been sufficient to neutralise the small number of infectious viruses. Although based on a single case of R2-4, it appears that the infectious dose could be as low as 16 copies, very similar to the 3-10 copies of WP HBV. ${ }^{23}$ In order to detect such low level of viral load, screening NAT should reach 0.8 copies or $0.15 \mathrm{IU} / \mathrm{mL}$ limit of sensitivity.

In conclusion, transfusion of FFP and, to a lesser extent, RBC components from donors with OBI undetected by the current highly sensitive NAT assays may be at risk of transmitting HBV infection to immunocompetent patients. HBV blood safety could be further improved by either anti-HBc screening, HBV DNA NAT with a LOD of 0.8 copies $/ \mathrm{mL}(0.15 \mathrm{IU} / \mathrm{mL})$ or pathogen reduction of blood components. Efficient haemovigilance system and long-term archiving of large volumes of both donors' and recipients' plasma samples pretransfusion are essential to identify and characterise HBV TTI in order to limit delays in the therapeutic management of infected patients.

Acknowledgements Donors and patients are thanked for participating in the look-back procedures and the staff of Blood Transfusion Centre of Slovenia, Ljubljana, and Transfusion Centre of General Hospital Celje for samples archiving and follow-up testing. Dr N Lelie is thanked for his help in evaluating the minimal infectious dose.
Contributors DC designed the study, performed molecular investigations, analysed data and wrote manuscript. SMA performed molecular experiments, contributed to data analysis, reviewed manuscript. SL contributed to experiment design, data analysis and manuscript writing. J-PA contributed to study design, data analysis and manuscript writing. SL-S designed the study, identified and collected samples, analysed data and wrote manuscript.

Funding This work was supported by a Grifols Diagnostics research grant to DC. Competing interests None declared.

Patient consent Not required.

Provenance and peer review Not commissioned; externally peer reviewed.

(c) Article author(s) (or their employer(s) unless otherwise stated in the text of the article) 2019. All rights reserved. No commercial use is permitted unless otherwise expressly granted.

\section{REFERENCES}

1 World Health Organization. Hepatitis B Fact sheet. 2017 http://www.who.int/ mediacentre/factsheets/fs204/en/

2 Vermeulen M, Dickens C, Lelie N, et al. Hepatitis B virus transmission by blood transfusion during 4 years of individual-donation nucleic acid testing in South Africa: estimated and observed window period risk. Transfusion 2012;52:880-92.

3 Raimondo G, Allain JP, Brunetto MR, et al. Statements from the Taormina expert meeting on occult hepatitis B virus infection. J Hepatol 2008;49:652-7.

4 Pondé RA. Molecular mechanisms underlying HBsAg negativity in occult HBV infection. Eur J Clin Microbiol Infect Dis 2015;34:1709-31.

5 Wang JT, Lee CZ, Chen PJ, et al. Transfusion-transmitted HBV infection in an endemic area: the necessity of more sensitive screening for HBV carriers. Transfusion 2002;42:1592-7

6 Satake M, Taira R, Yugi $H$, et al. Infectivity of blood components with low hepatitis B virus DNA levels identified in a lookback program. Transfusion 2007;47:1197-205.

7 Levicnik-Stezinar S, Rahne-Potokar U, Candotti D, et al. Anti-HBs positive occult hepatitis B virus carrier blood infectious in two transfusion recipients. J Hepatol 2008;48:1022-5.

8 Su TH, Chen PJ, Chen TC, et al. The clinical significance of occult hepatitis B transfusion in Taiwan--a look-back study. Transfus Med 2011;21:33-41.

9 Yuen MF, Wong DK, Lee CK, et al. Transmissibility of hepatitis B virus (HBV) infection through blood transfusion from blood donors with occult HBV infection. Clin Infect Dis 2011;52:624-32.

10 Allain JP, Mihaljevic I, Gonzalez-Fraile MI, et al. Infectivity of blood products from donors with occult hepatitis B virus infection. Transfusion 2013:53:1405-15.

11 Taira R, Satake M, Momose $S$, et al. Residual risk of transfusion-transmitted hepatitis $B$ virus (HBV) infection caused by blood components derived from donors with occult HBV infection in Japan. Transfusion 2013;53:1393-404.

12 Seed CR, Maloney R, Kiely P, et al. Infectivity of blood components from donors with occult hepatitis $B$ infection - results from an Australian lookback programme. Vox Sang 2015;108:113-22.

13 Lieshout-Krikke RW, van Kraaij MG, Danovic F, et al. Rare transmission of hepatitis B virus by Dutch donors with occult infection. Transfusion 2016;56:691-8.

14 Candotti D, Allain JP. Transfusion-transmitted hepatitis B virus infection. J Hepatol 2009;51:798-809.

15 Kleinman SH, Lelie N, Busch MP. Infectivity of human immunodeficiency virus-1 hepatitis $C$ virus, and hepatitis $B$ virus and risk of transmission by transfusion. Transfusion 2009:49:2454-89.

16 Candotti D, Lin CK, Belkhiri D, et al. Occult hepatitis B infection in blood donors from South East Asia: molecular characterisation and potential mechanisms of occurrence. Gut 2012;61:1744-53

17 Leung VK, Lee CK, Chau TN, et al. A probable case of transfusion-transmitted hepatitis $B$ virus infection in an immunosuppressed recipient caused by an occult $\mathrm{HBV}$-infected donor with negative ID-NAT. Transfus Med 2010;20:276-7.

18 Weusten J, van Drimmelen $\mathrm{H}$, Vermeulen $\mathrm{M}$, et al. A mathematical model for estimating residual transmission risk of occult hepatitis $B$ virus infection with different blood safety scenarios. Transfusion 2017:57:841-9.

19 Zahn A, Li C, Danso K, et al. Molecular characterization of occult hepatitis B virus in genotype E-infected subjects. J Gen Virol 2008;89:409-18.

20 Candotti D, Grabarczyk P, Ghiazza P, et al. Characterization of occult hepatitis B virus from blood donors carrying genotype A2 or genotype D strains. J Hepatol 2008;49:537-47.

21 Klemenc $P$, Vidic B, Fratnik Steyer A, et al. Hepatitis $B$ virus genotypes in blood donors in Slovenia [Abstract]. 20 ${ }^{\text {th }}$ : ESCV, 2017:115.

22 Power JP, El Chaar M, Temple J, et al. HBV reactivation after fludarabine chemotherapy identified on investigation of suspected transfusion-transmitted Hepatitis B virus. J Hepatol 2010;53:780-7.

23 Lelie $\mathrm{N}$, et al Occult HBV infection and blood safety: a review. In: Allain J-P, Fu $Y$, Li C, Raimondo G, eds. Occult hepatitis B infection. . Beijing: Science Press, 2015:2015. 210-32. 